\title{
An Analysis of Organizational Conflicts in the Egyptian Context
}

\author{
Dr. Amany I. Shahin \\ Associate Professor \\ Faculty of Commerce \\ Department of Management \\ Helwan University \\ Helwan, Cairo Governorate, Egypt
}

\begin{abstract}
The purpose of this paper is to investigate the relation between strategies of managing organizational conflicts and productivity factors (knowledge, experience, behavior and disputes). The study aims to identify this relation in the Egyptian environment, and to highlight the main factors influencing teachers and official employees. Data were collected through a questionnaire survey from 121 Egyptian teachers and official employees from different age groups. Hypotheses were tested and analyzed by means of a correlation analysis. Indeed, most of the strategies of managing organizational strategies have a positive relation on productivity in the Egyptian environment. This shows us a clear measure in the Egyptian Educational System. Findings of this study were interesting and give a guide to managerial policy makers.
\end{abstract}

Keyword: Cooperation Strategy, Controlling Strategy, Avoidance Strategy, Absorption Strategy Compromise Strategy, Knowledge, Experience, Behavior, Disputes.

\section{Introduction}

This paper aims to understand the concept of organizational conflict in the Educational Sector in Egypt and its impact on the performance of teachers and office employees. The overlapping definitions of organizational conflict lead to different results in the performance of employees. It is one of the major factors affecting management. It is the actual or perceived opposition of needs, values and interests between people working together. Organizational conflict is a disagreement by individuals or groups within the organization, which can center on factors ranging from resource allocation and divisions of responsibility to the overall direction of the organization. Organizational conflict produces negative outcomes. Conflicts could cause stress, which reduces worker performance. On the other hand, organizational conflict represents an opportunity for productive change. The link between organizational conflict and productivity caused the concept to be very difficult. Reaching a world-wide application model to investigate organizational conflict is actually very difficult. The world of organizational conflict needs a great deal of investigation.

\section{Organizational Conflict: Defined:}

In modern society there is growing potential for conflict and also growing much need for conflict management. Conflict management aims to integrate the organizational level and personal level.

\section{Traditional Conflicts}

Traditionally conflict was considered the differences between people or groups in objectives, ideas and methods of facing obstacles. Schmidt and Kochan (1972) define conflict to be a perceived opportunity which exists for interfering with the other's goal attainment. Actually, conflict is the difference between people, groups and organizations in their objectives (Hocker\&Wilnat, 1985). It is an interactive state that appears in the differences between individuals and groups and this could appear between or inside social entities.

Conflict is the difference or disturbance that appears on the behavior of people and this causes a whole deterioration of decision making process inside the organization. It is a sort of attack to security (Haniti,1993). El-Karyouni (2003) views organizational conflict as the negative impact on the second party aiming to avoid him from achieving his objectives. Rahim (2011) described that conflict can be functional by stimulating innovation, creativity, and change; improving decision making processes; and forcing individuals and/or groups to search for new approaches. Serfi (2008) descrided conflict as an influence for changes in any organization. Organizational Conflict is not only negative but it has many positive sides such as creativity, solving problems and facing obstacles which faces employees. (Farayat, 
Lousi, and Shehab 2009). Aziz (2012) identified that conflict exists in the lives of individuals, groups and organizations and this is normal as it refers to interaction.

Organizational conflict appears as mentioned previously because of the conflict in objectives and opinions on the individual and organizational levels (Haseeb, 2015).Conflict occurs horizontally (within levels of an organization) or vertically (between different levels of an organization). Each type of conflict will have different consequences for the organization. (Flink,2015)

Over time conflict exists among people, groups and organizations. It is a main factor affecting the performance of work. However, over the years conflict involved other aspects which affect the quality of work.

\section{Modern Conflicts}

Conflict of interest (COI) is a major factor of conflict and has a major impact on quality and performance. In this regard it is important to strengthen the sense of responsibility, revise work processes, define the role and authorities of beneficiaries, formulation, implementation and monitoring ethical guidelines and coordination between personal and organizational goals.(Ghasemi et al,2019)

Conflict can be a significant dysfunction by causing stress, burnout, and dissatisfaction; decreasing communication between groups and individuals; damaging the lines of trust within relationships; lowering commitment levels; and increasing resistance to change.

Despite the negative connotation associated conflict. It can have a positive impact on many aspects. The organizations and individuals must effectively learn to manage impending conflicts to foster successful outcomes. (Annacone,2017).

In the Modern view, an organization or group with no conflict is more likely to become static, non-responsive, inflexible and unadoptable. It states that a minimum level of conflict is actually beneficial for the organization, because it maintains a certain level of creativity and competition among the individuals. (WWW.Qura.Com).

\section{Types of Conflicts}

Qaryouti (2009) and Omyan (2008) discuss that organizational conflict levels are arranged as follows: 1) Conflict on an Individualistic Level. 2) Conflict between Individuals. 3) Conflict on Group Level. 4) Conflict on the Organizational Levels. Effects of Organizational Conflict were observed by Ababneh (2008), as those who find positive effects of a conflict and others who find negative effects.

Jurban (2017) identified 3 types of conflicts, (1)The degree of functional independence: Members of an organization work in different departments having different responsibilities, which is most likely to create conflicts if not entertained separately. (2) The difference in values and goals: A major source of conflict between workers in different departments arises when they have different goals against each other. (3) Overlapping powers and responsibilities within the organizational structure: When the responsibilities and powers of the individuals interfere with each other.

\section{Other conflicts which exist in an organization include:}

Problem in communication: The poor human relations among organizational members, the lack of an appropriate information process could eliminate mutual understanding between organizational members (Tourish and Hargie, 2004)

Role ambiguity: When there is a lack of clarity in the role and the job requirements then the employee is in a difficult working environment and this may lead to an unexpected pattern of behavior (Mullins, 2007). Studies found negative effects of role conflict and role ambiguity, however other studies found beneficial effects because they create space for defining the role expansively (Ebbers and Wijnberg 2017)

Conflict of interest: The allocation of limited resources may be a cause for conflict because each entity might need to fight for its own share (Mullins, 1996)

Omisore \& Abiodun (2014) identified different types of conflict, Functional or Constructive Conflict: this argues that all conflicts are good. Rather, some conflicts support the goals of the group and improve its performance; these are functional or constructive forms of conflict. The argument is that if conflict leads to normal competition among groups and the group works harder and produce more, it is advantageous to the group and the organization. While, Dysfunctional or Destructive Conflict: there are conflicts that hinder the group performance. Conflict if not effectively handled can tear relationships apart and, thus, interfere with the exchange of ideas, information and resources in groups and between departments. 


\section{Egyptian Organizational Conflicts}

\section{Egyptian Education}

Egypt is located in a unique geographical location; it is a country bordering Africa, Asia and Europe (Hopwood, 1993). The Nile, which cuts through Egypt, has helped population to settle around the Nile valley and to cultivate its fertile This has helped to rise of the ancient Egyptian Civilization one of the oldest human civilizations.

This civilization has laid the foundations for most of the world's current civilizations. It was based on an effective education system. Such a system that has, for example, produced architects who built the famous pyramids, physicians and surgeons who performed delicate medical operations, chemists who mummified bodies of pharaohs in a manner that has preserved these bodies for several thousand years using techniques that still bewilder scientists.

Such an education system has also produced the first known accountants and auditors in history (Woolf,1912). It has produced astrologists who could place the statue of the Pharaoh Ramses in a certain location where the sun would shine on his face only twice each year, on his birthday, and on the day he has ascended the throne. Archaeologists are still discovering new secrets of this civilization whose secrets never seem to end.

Egypt has passed in the following years through periods of ups and downs. Evidently the education system was affected by these fluctuations through the years. The eighteenth century has been a period of deterioration and isolation to the extent that the invasion of Egypt by Napoleon Bonaparte in 1798 has produced a cultural shock as the Egyptians were faced by mysteries they never heard of, such as the artillery which caused panic as well as other erstwhile modern inventions. The only education system available at the time was mainly religious education and some related studies including language study of only one language. The only university education was "Al-Azhar" University, a university which was founded in the year 972 for religious education (Amar,2005).

\section{Conflicts in the Egyptian Education}

The student in Egypt requires education to provide them with a greater value. Actually, in Egypt we find that education certificate is of a great value. In the Egyptian society satisfaction extends from the student's satisfaction to have a higher education certificate to include the view of members of society to them. However, Holmes (2008) believes that the Egyptian public university system does not prepare students for career opportunities and this leads to unemployment following graduation. Although faced with this possible problem which could decrease satisfaction, we find that the demand for higher education is still very high from Egyptian consumers. Students usually demand a public or a private university. If they have the financial ability they have an extra option to join a private (non-governmental) university. The demand for higher education is of great importance it indicates a demand for the university or the higher institution degree.

Mousa \& Mousa (2009) investigated the issue of developing countries and referred to the importance of the encouragement of the government of the public and private education as well as the need to educate and train educators.

Egypt as a developing country requires a link between the university and the society in particular in areas related to teaching research and social services (Amar 1996). Also Ali (1998) referred to the importance of the university past and present education in order to deal with future problems.

\section{Conflicts in the Egyptian Organizations}

Although centralization of power seems to be a dominant factor of the Egyptian culture, recent researches show a trend towards participation, as a way of sharing decision making. From an investigation in 31 Egyptian State owned organizations, Badran and Hinings (1981) found that these organizations are highly structured and highly centralized. From Another study of 825 Egyptian public employees, Palmer et al (1985) found that Egyptian officials attempted to concentrate as much authority as possible in their hands and they tended to resist the delegation of authority. They considered three themes, the first was historical in nature, the second stressed the patriarchal nature of the Egyptian culture, and the third theme considered centralization as motivated by personal concerns of power. Kabasakal and Bodour (2002) studied the common managerial aspects between Morocco, Turkey, Kuwait and Qatar. This was the Arab cluster of the Globe Project. It was considered a cluster as they have been under the influence of Europe and Ottman Empire. It was found that these countries' leadership includes team oriented and charismatic attributes. The result of this research is another support of the two dominant factors of the Egyptian culture which are social integration and concentration of power. According to Hofstede (1980) Arab countries such as Egypt are characterized by high power distance and high uncertainty avoidance. Hickson and Pugh (1995) wonderfully described the Arab culture as having two paradoxes, first Arabs are disposed to handle authority with high power distance, yet at the same time they aspire to an open door for all comers, high or low consultation in the manner of sheikhs. 
Secondly, They pursue their own individual interests yet do so by collectivistic means through personal relationships. (Hickson and Pugh, 1995, pp.195-196). Other researchers found that Egyptian managers consider participation as one of the most important managerial aspects in organizations. From a study of 17 Egyptian industrial organizations, Elgamal (1993) found differences in managerial profiles which revolved around planning and issues of participation. Parnell and Hatem (1999) compared the Egyptian and American management styles. The study was conducted at the American Chamber of Commerce in Egypt. The Egyptian sample reflected the desire for participative style of leadership.

Atiyah (1992) concluded that the main features of organizations and management in Arab countries are over centralization and emphasis on control. However, he notes that the results with respect to leadership styles of Arab managers are conflicting. Some follow an authoritarian style, which could be linked to the traditional leader in Arab societies, while others follow a consultative style.

Actually we find that some researchers identified the existence of concentration of power as a main dominant factor controlling public organizations in Egypt and therefore conclude that it has a wide impact on leadership (Palmer et al, 1985; Badran and Hinings, 1981; Kabasakal and Bodour, 2002) while others referred to the existence of participation for Egyptian leadership styles (Elgamal, 1999; Parnell and Hatem, 1999).This conflict requires massive research in this area in order to fulfill this gap.

\section{Managing Organizational Conflict}

There are many strategies for resolving organizational conflict, but the best method depends on the situation. Rahim (1986) determined different methods to deal with organizational conflicts which are: The Integrated Style- It is about exchange of information between parties and reaching an effective solution for them. Leaning for help Style- The individual who is leaning for help scarifies with his interests for the sake of other parties. Controlling Style- This method is a method which uses all ways to achieve the targeted objectives Avoidance Style- This method escapes responsibility it plans to avoid any responsibility The Conciliator Style- This method depends on the give and take method each party sacrifices to gain and to reach an optimal decision.

Gawad (1995) indicated that strategies that deal with organizational conflict depends on avoidance, bargaining, forcing, confrontation and calming down. While Harer (1997) recommended using avoidance, facing, competition and cooperation to deal with organizational conflicts. El-Saad and El- Mola (1999) recommended using acquisition, diversification, competitive advantage, mutual benefits and finally liquidation.

While Hellriegel et.al.(2001) determined other strategies to resolve organizational conflict as follows: 1) The Cooperation Strategy-This strategy aim to reach a solution which satisfies all parties. 2) The Controlling Strategy- It is a restrictive strategy. The user of this strategy aims to achieve his objective without caring about others. 3) Avoidance Strategy- It is a strategy which is neither cooperative nonrestrictive; this method avoids any problems and tries to escape it. 4) Absorption Strategy- This strategy aims to absorb the conflicts which the different parties have. 5) Compromise Strategy-This strategy aims to give partial care for each party in order to achieve partial satisfaction to be able to face challenges.

\section{Methodology}

This research is a hypotheses testing research. Convenience sampling was used to collect data. Convenient sampling was used because it was considered quick and less expensive. The nature of the Egyptian teachers and administrative employees in El Manara School were investigated. The research aims to investigate the relationship between Managing organizational conflicts (Cooperation, Controlling, Avoidance, Absorption and Compromise) and Productivity (knowledge, experience, behavior and disputes)

A likert scale was used for the first 5 items. (1) referred to strongly agree (2) agree (3) neutral (4) disagree and (5) strongly disagree. This indicated that (1) strongly agree referred to a very high degree of acceptance or very low degree of refusal, while (5) strongly disagree referred to a very low degree of acceptance a very high degree of refusal.

\section{Research Hypotheses}

This study aims to test the following hypotheses:

$\boldsymbol{H} \mathbf{1}$ There is a positive correlation between Managing organizational conflicts and Knowledge

$\boldsymbol{H} 2$ There is a positive correlation between Managing organizational conflicts and Experience.

H3There is a positive correlation between Managing organizational conflicts and Behavior of employees.

H4There is a negative correlation between Managing organizational conflicts and Disputes of employees. 
The survey included different occupations and age groups of Egyptian employees. Questionnaires were distributed to Egyptian teachers and administrative employees in El-Manara School. The results were a total of 121 usable responses from 200 distributed questionnaires.

Table 1.1 Question and Related variables

\begin{tabular}{|l|l|}
\hline Questions & Variables \\
\hline $\begin{array}{l}\text { 1)Listens to all views till reaching a solution } \\
\text { 2)Helps employees to reach a solution for their problems }\end{array}$ & Cooperation Strategy \\
\hline $\begin{array}{l}\text { 3)Uses his power for stimulating actions } \\
\text { 4) Uses his power to stimulate his ideas }\end{array}$ & Controlling Strategy \\
\hline $\begin{array}{l}\text { 5)Ignores all of employees' problems } \\
\text { 6) Avoids all problems }\end{array}$ & Avoidance Strategy \\
\hline $\begin{array}{l}\text { 7)Tries to fulfill the needs of the employees } \\
\text { 8)Obeys the employees views }\end{array}$ & Absorption Strategy \\
\hline $\begin{array}{l}\text { 9)Negotiates with the employees to reach a solution that satisfies them } \\
\text { 10) Suggests a compromise solution to solve problems }\end{array}$ & Compromise Strategy \\
\hline 11) There is a gap in the employees level of knowledge & Knowledge \\
\hline 12)There is a lack in the level of experience & Experience \\
\hline 13)The behavior of employees are positive & Behavior \\
\hline 14)There are many disputes between employees & Disputes \\
\hline
\end{tabular}

As the hypotheses were mentioned previously we are going to see how they are investigated by variables.

Table 1.2 Hypotheses and Variables investigated

\begin{tabular}{|l|l|}
\hline H1 & Q.1-10and Q.11 \\
\hline H2 & Q.1-10and Q.12 \\
\hline H3 & Q.1-10 and Q.13 \\
\hline H4 & Q.1-10and Q.14 \\
\hline
\end{tabular}

The questionnaire was divided into two sections. The first section was descriptive. It included information about the type of work, age and experience. The second section included information about Managing organizational conflicts (Cooperation, Controlling, Avoidance, Absorption and Compromise Strategies) and Productivity (knowledge, experience, behavior and disputes).

A correlation analysis was conducted to measure the association of Managing organizational conflicts and productivity factors as independent variables on the Egyptian employees' in El Manara School. El- Manara School was chosen as a moderate school, it is called Tagribi School. This school is a public school with some aspects of the private sector, such as the fees and the curriculum.

Actually, a correlation analysis was conducted to measure the association between managing organizational conflicts and productivity. The idea of correlation is one of the basic in the elaboration of bivariate relationships. (Bryman and Cramer, 1998).Correlation indicates the strength and direction (positive or negative) of the relationship between a pair of variables (Amin, 2008). In our study we will use Pearson Product Moment Correlation because this measurement is suitable for our variables which are considered interval.

\section{Tables 1.3 - 1.4 show the Correlation analysis}

Table 1.3 The correlation between Strategies of Managing Organizational Conflicts, knowledge and experience

\begin{tabular}{|l|l|l|l|l|l|}
\hline $\begin{array}{l}\text { Strategies of } \\
\text { Organizational Conflict }\end{array}$ & $\begin{array}{l}\text { Cooperation } \\
\text { Strategy }\end{array}$ & $\begin{array}{l}\text { Controlling } \\
\text { Strategy }\end{array}$ & $\begin{array}{l}\text { Avoidance } \\
\text { Strategy }\end{array}$ & $\begin{array}{l}\text { Absorption } \\
\text { Strategy }\end{array}$ & $\begin{array}{l}\text { Compromise } \\
\text { Strategy }\end{array}$ \\
\hline Knowledge & .091 & .147 & $.243^{* *}$ & $.222^{*}$ & .091 \\
\hline Sig.(2 tailed) & .319 & .107 & .007 & .014 & .321 \\
\hline Experience & -.053 & $.300^{* *}$ & $.359^{* *}$ & $.272^{* *}$ & -.089 \\
\hline Sig.(2 tailed) & .564 & .001 & .000 & .002 & .330 \\
\hline
\end{tabular}

** Correlation is significant at the 0.01 level (2-tailed).

*Correlation is significant at the 0.05 level (2-tailed). 
Table 1.3 shows that knowledge does not have a relationship with the Cooperation strategy, Controlling strategy and the Compromise strategy. This indicates that increasing the knowledge of employees is not related to those factors. While the Avoidance strategy and the Absorption strategy does have a positive relationship with knowledge. Avoidance strategy has a relationship with knowledge at $.243 * *$ sig at.007. This indicates that avoidance of problems give the employees the time and energy to increase their knowledge. Also the Absorption strategy has a relationship with knowledge at .222* sig at .014 so absorbing employees and caring for them has a positive effect on Egyptian employees they feel secure and appreciated and this increases their desire to increase knowledge. So our first hypothesis is partially accepted.

On the other hand there is no relation between Experience and neither the Cooperation nor the Compromise strategy. However there is a positive relation between Experience and Controlling, Avoidance and Absorption strategies. The relation between Experience and Controlling strategy is .300** sig. at .001, indicating that experience increases when there is a controllable and systematic system. While the relation between Experience and Avoidance Strategy is . $359 * *$ sig. at .000 this shows that avoidance and when there are no problems could enable employees to concentrate and increase their experience. Finally, There is a relation between Experience and Absorption Strategy is .272** sig. at .002 indicating that caring and support increases the individual's ability to gain experience. So our second hypothesis is partially accepted.

Table 1.4 The correlation between Strategies of Managing Organizational Conflicts, Behavior and Disputes

\begin{tabular}{|l|l|l|l|l|l|}
\hline $\begin{array}{l}\text { Strategies of } \\
\text { Organizational Conflict }\end{array}$ & $\begin{array}{l}\text { Cooperation } \\
\text { Strategy }\end{array}$ & $\begin{array}{l}\text { Controlling } \\
\text { Strategy }\end{array}$ & $\begin{array}{l}\text { Avoidance } \\
\text { Strategy }\end{array}$ & $\begin{array}{l}\text { Absorption } \\
\text { Strategy }\end{array}$ & $\begin{array}{l}\text { Compromise } \\
\text { Strategy }\end{array}$ \\
\hline Behavior & -.110 & $.432^{* *}$ & $.191^{*}$ & $.181^{*}$ & .041 \\
\hline Sig.(2 tailed) & 230 & .000 & .036 & .047 & .656 \\
\hline Disputes & -.125 & $.366^{* *}$ & $.428^{* *}$ & .134 & -.063 \\
\hline Sig.(2 tailed) & 171 & .000 & .000 & .142 & .495 \\
\hline
\end{tabular}

** Correlation is significant at the 0.01 level (2-tailed).

*Correlation is significant at the 0.05 level (2-tailed).

Table 1.4 shows us that Behavior has no relation with Cooperation and Compromise Strategies. While, it has a positive relation with Controlling, Avoidance and Absorption Strategies. The relation with Controlling Strategy is .432** Sig. at .000 indicating that controlling individuals and systemizing them has a large positive relation on behavior. While, the relation between Behavior with Avoidance is .191* Sig. at .036 indicating that avoiding problems has positive relation with Behavior but a weak relation. Finally, the relation between Behavior and Absorption is .181* Sig. at .047 indicating a positive but weak relation. Caring and support is to some extent important for Egyptian employees. This partially accepts our Third hypothesis.

On the other hand, Disputes do not have a relation with Cooperation, Absorption and Compromise Strategies. While, it has a positive relation with Controlling and Avoidance Strategies. The relation with Controlling Strategy is .366** Sig. at .000 . This indicates that disputes are not controllable and not restricted with the Controlling Strategy. While, the relation between Disputes and Avoidance Strategy is .428** Sig. at .000. Avoiding problems and obstacles are considered very important in increasing disputes in the Egyptian culture, there is a strong relation between them. Facing problems could be a great solution to many disputes. This partially accepts our forth hypothesis.

\section{Discussion}

The results of the study supported some of our hypotheses. According to the correlation analysis, the Strategies of Managing Organizational Conflicts has a positive relation with Knowledge, Experience, Behavior and Disputes. Knowledge does not have any relation with the Cooperation strategy, Controlling strategy and the Compromise strategy. So knowledge of employees is not related to those factors. While the Avoidance strategy and the Absorption strategy have a positive relationship with knowledge. Avoidance and neglecting problems give the employees the time and energy to increase their knowledge. Also so absorbing employees and caring for them has a positive effect on Egyptian employees they feel secure and appreciated and this increases their desire to gather information and increase knowledge.

On the other hand Experience has no relation with the Cooperation and the Compromise strategy. However there is a positive relation between Experience and Controlling, Avoidance and Absorption strategies. Experience increases when there is a controllable and systematic system. While avoidance of problems and neglecting them could be an advantage in the Egyptian culture. When the employees feel that there are no problems this enables employees to concentrate and increase their experience. Finally, the absorption, caring and support increases the individual's ability to gain experience. 
Behavior has no relation with Cooperation and Compromise Strategies. While, it has a positive relation with Controlling, Avoidance and Absorption Strategies. Controlling individuals and systemizing them has a large positive relation on behavior. They work in a particular frame. While, avoiding problems has positive relation, but weak relation with Behavior. Employees feel that there are no problems so they act positively, but for a limited time.

Although avoiding the problem is not a solution as they could be faced with a disaster. Finally, absorption, caring and support is to some extent important for Egyptian employees as it improves the behavior. On the other hand, Disputes do not have a relation with Cooperation, Absorption and Compromise Strategies. While, it has a positive relation with Controlling and Avoidance Strategies. Disputes increase with a controllable and restricted environment. The Egyptian employees' disputes increases when they feel ordered and controlling. Avoiding problems and obstacles are considered very important in increasing disputes in the Egyptian culture. Facing them could be a great solution to many disputes.

\section{Conclusion \& Recommendations}

The study investigates the Managing Organizational Conflicts and its relation with knowledge, experience, behavior and disputes. It is essential to design a program that increases the Egyptian employee productivity. Conflicts will always exist in any organization and in any time. It is not always a disadvantage but sometimes it is a benefit. However, dealing with conflicts is a must to keep the organization surviving and successful. It is important to consider the following:

- Increase the availability of information and knowledge for Egyptian employees' through subscription in different periodicals and training programs. This will enable the employee to increase his experience and to focus on his work to produce higher quantity and better quality.

- Orient the Egyptian employees to accept and deal with any changes in the organization.

- Ensure that employees organize their time and appreciate the importance of time

- Create a boundary so that employees work within

Further research is needed to illustrate the managerial policies required to direct and encourage productivity in Egypt, whether in the educational sector or other sectors. More questions may be needed to elicit more information on productivity. This issue is worthy of further research.

\section{References}

Amar, Hamid (1996) University As a Mission and an Institution, Cairo: Maktabit Eldar Elarabia lil kitab (In Arabic)

Amar, Hamid (2005) The Historical Development of Egyptian Education, Cairo: Maktabit Eldar Elarabia lil kitab (In Arabic)

Amin, Osama Rabea (2008) Statistical Analysis for different variables by using SPSS, Egypt: Monofya University (In Arabic)

Annaccone, Adam R. (2017) Identifying Interpersonal Ccnflict and Conflict Management Strategies in Collegate/University Athletic Traning: A Descriptive Study, A Dissertation Submitted to the School of Graduate Studies and Research in Partial Fulfillment of the Requirements for the Degree Doctor of Education, Indiana University of Pennsylvania

Atiyah, H.S (1992) Research Note: Research in Arab Countries, Organization Studies, 13(1):105-110

Aziz, Khaled Mahmoud (2012) Organizational Culture and its relationship with methods of dealing with organizational conflicts Journal of Scientific Physical Education, Babylon University, pp.48-71(in Arabic)

Badran, M. and Hinings, B. (1981) Strategies and Administration Control and Contextual Constraints in a less developed Country: The Case of Egyptian Enterprises, Organization Studies, Vol. 2, No.1, pp.3-21

Bryman A. and Carmer D. (1998) Quantitative Data Analysis With SPSS Release 10 for Windows, East Sussex: Routledge.

Ebbers, Joris J and Wijnberg, Nachoem M(2017) Betwixt and between: Role conflict, role ambiguity and role definition in project-based dual-leadership structures, human relations, Vol. 70, No.11, pp. $1342-1365$

Elgamal, M. A. (1993) An Investigation of the Managerial Practices of Egyptian Managers and Implications for Effectiveness, Arab Management Group Proceedings, Arab Management Conferences, University of Bradford U.K., 6-8 July.

El Saad, Moslem and El Mola, Abd el Rahman (1999) Conflict between Organizations, Journal of Economic Studies: Basra (in Arabic)

El Sarfi (2008) The Managerial Decisions and its Support System, Alexandria- Dar El Fikr el Gameii llnashr (in Arabic)

Faryhat, KidrKazim, El louzi, mousa and Shehabi, Enam (2009) Organizational Behavior Contemporary Concepts, Jordan: Dar Ithraallnashr (in Arabic) 
Flink ,Carla M.(2015) Multidimensional Conflict and Organizational Performance, American Review of Public Administration, Vol. 45, No.2,pp.182-200

Gawad, ShawkiNagi (1995) Business Management a Macro Perspective, Bagdad:Dar El Kotob 11 Tebaha (in Arabic)

Ghasemi, Morteza, Samadi, Abdolsamad, Anbari, Zohreh, Amini, Saeed, (2019) Study the relation between factors effecting on creating conflict of interests and quality of care: The case of Ayat-Allah-Taleghani hospital, Arak, Iran, Medical Science, Vol.23, No.98,pp. 577-585

Harer, Hussein (1997) Organizational Behavior ,Jordon :El Zahran llnashr (in Arabic)

Haniti, Mohamed Falleh (1993) Organizational Conflict; Its Reasons, Methods of Management in Public and Private Organizations in Jordan, Social Sciences Studies, March, pp.30-69(in Arabic)

Haseeb, El-sayed Ahmed Fathi (2015) The Impact of Managerial Strategies of Organizational Conflict and Organizational Subsidy on Organizational Development, Empirical Study on Taxation of Products, Journal of Financial and Commercial Researches, Faculty of Commerce, Port Said University(in Arabic)

Hellriegel, Don, Slocum, John and Woodman, Richard (2001) Organizational Behavior: Cincinnati: Ohio State

Hickson, D.J. and Pugh, D.S (1995) Mangement Worldwide: The Impact of Sociatel Culture on Organization Around the Globe, London: Penguin

Hocker, J. L., and W. W. Wilmot (1985) Inter personal conflict, Dubuque, Iowa: Wm. C. Brown Publishers

Hofstede, G. (1980) Culture's Consequences International Differences in Work Related Values, Biverly Hills: C.A:Sage

Holmes, Mary Tyler E. (2008) Higher education reform in Egypt: preparing graduates for Egypt's changing political economy, Education, Business and Society: Contemporary, Middle Eastern Issues, Vol.1, No.3,pp.175-185.

Hopwood, D (1993) Egypt: politics and society 1945-1990, New York: Routledge.

Jubran, Ali Mohammad (2017)Organizational Conflict among Teachers and the Principal's Strategies of Dealing with It from the Teachers' Perspective in Schools of Jordan, Journal of Education and Learning; Vol. 6, No. 1, pp. 54-71.

Kabbasakal, H. and Bodour, M. (2002) Arabic Cluster: A Bridge Between East and West, Journal of World Business, Vol.37, No.1, pp.60-67

Karouni, Mohamed Kasim (2003) Organizational Behavior-Study of Personality Behavior (Individuals and Groups) in Different Organizations, Amman-Jordan- Dar El-Shark.(in Arabic)

Moussa, Nabil \&Moussa, Sandra (2009) Quality assurance of e-learning in developing countries, Nonlinear Analysis, Vol.71, pp.32-34.

Mullins LJ (1996) Management and Organisational Behaviour. 4th ed. London: Pitman. Mullins LJ (2007)Management and Organisational Behaviour. 8th ed. Upper Saddle River, NJ: Prentice-Hall.

Omyan, M. (2008) Organizational behavior in business organizations (4th ed.). Jordan, Dar Wael for publication and distribution.

Omisore,Bernard Oladosu\&Abiodun ,Ashimi Rashidat (2014) Organizational Conflicts: Causes, Effects and Remedies, International Journal of Academic Research in Economics and Management Sciences, Vol. 3, No. 6, pp.118137.

Palmer, M., Yassin, E., and Leila, A. (1985) Bureaucratic Flexibility and Development in Egypt, Public Administration and Development, Vol.15, No.4, pp.323-337

Parnell, J.A and Hatem, T. (1999) Cultural Antecedents of Behavioral Differences Between American and Egyptian Managers, Journal of Management Studies, Vol.36, No.3,pp.399-418

Qaryouti, M. (2009) Organizational behavior: The research of individual and collective human behavior in work organizations. Jordan: Dar Wael for publication and distribution.

Rahim M.A. (1986) Referent Role \& Styles OF Handling Interpersonal Social Psychology Vol ,26 No.1 pp.79-86

Rahim, A. (2011) Managing conflict in organizations Piscataway, NJ: Transaction Publishers.

Schmidt, S. M., and T. A. Kochan (1972) Conflict: toward conceptual clarity Administrative Science Quarterly 17, pp. 359-370.

Tourish D and Hargie O (2004) Motivating critical upward communication: a key challenge for management decision making. In: Tourish D and Hargie O (eds) Key Issues in Organizational Communication, London: Routledge, pp.188-204.

Woolf, Arthur H. (1912) A short history of accountants and accountancy, London: Gee \& Co Ltd. WWW.Qura.com 